\title{
DROP OUT FROM SCHOOL AMONG GIRLS IN EDO STATE: IMPLICATIONS FOR COUNSELLING
}

\author{
ALIKA, Ijeoma Henrietta PhD \\ Lecturer \\ Department of Educational Psychology and Curriculum Studies \\ Faculty of Education \\ University of Benin \\ Benin City, Nigeria. \\ e-mail: henriettaalika@yahoo.co.uk \\ and \\ EGBOCHUKU, Elizabeth Omotunde PhD \\ Associate Professor \\ Department of Educational Psychology and Curriculum Studies \\ Faculty of Education \\ University of Benin \\ Benin City, Nigeria. \\ e-mail: mamandidi@yahoo.co.uk
}

\begin{abstract}
Drop out from school among girls is a global phenomenon. In Nigeria, girl's dropout from school for various reasons like early marriage, pregnancy, religious factors, socio-economic factors, school related factors and ill health. The focus of this paper is to investigate why girls dropout from school in Edo State. The descriptive survey method was adopted for this study. A checklist on reasons for drop out was used in gathering information from the respondents. From a pool of primary schools, secondary schools and skill acquisition centres in Benin City, four primary schools, four secondary and four skills acquisition schools were randomly selected for the study. Data was analysed using percentages. Poverty had the highest percentage (53\%), while death of parents, pregnancy, ill health, inadequate teaching had the least percentage of $1 \%$. It is recommended that counsellors should identify indigent students, who are likely to dropout of school as a result of poverty, and help negotiate some form of scholarship or financial assistance for them.
\end{abstract}

Key Words: dropout, school, girls, counselling. 


\section{Introduction}

Education enables girls to make their own decisions and to influence their families positively. Education saves and improves the lives of girls and women. It allows them greater control of their lives and provides them with skills to contribute to their societies. UNICEF (2004) report indicates that girls' education leads to more equitable development, stronger families, better services, better child health and effective participation in governance. Despite the obvious benefits of Education to national development, research findings indicate that girls' dropout rate from school is higher than that of boys. Osakwe, Osagie, Madunagu and Usman (1995) observed that Nigerian girls, for various reasons bordering on religious, cultural, socio-economic and school related factors, are not given a fair chance in the educational sector. In Nigeria, about 7.3 million children do not go to school, of which 62\% are girls (UNICEF 2004). The same UNICEF report indicates that girls' primary school completion rate is far behind that of boys, at $76 \%$ compared with $85 \%$ for boys. This gender gap means that millions more girls than boys are dropping out of school each year. This goes to show that the majority of children not in school are girls. UNICEF (2003) showed a worrisome report from subSaharan Africa where the number of girls out of school rose from 20 million in 1990 to 24 million in 2002. The report also indicated that $83 \%$ of all girls out of school in the world live in Sub-Saharan Africa, South Asia, East Asia and the Pacific.

Mohammed (2004) equally reported that a girl may be withdrawn from school if a good marriage prospect arises. Early marriage is a sociocultural factor that hinders the girl child's access to school. Some parents, in an attempt to protect their teenage daughters, give them out to wealthy old friends. Some of these girls who attempt to escape from such forced marriages end up in disaster. Efforts should be made to ensure that girls go to school and complete their schooling. According to Egbochuku (2002), efforts made to ensure that adolescent girls who re-enrolled in school are retained with a view to acquiring education will permanently close the door to poverty and ignorance and at the same time open that of prosperity in terms of economic buoyancy, social advancement and civilization.

Alika and Egbochuku (2009) found that the socio-economic status of the girls imposes considerable constraints upon their continuing stay in school. In fact, they asserted that a girl's particular socio-economic inheritance may have a direct and important effect on educational attainment. 


\section{The Problem}

Education, which is the right of every child, is a mirage in the lives of some Nigeria girls because some of them are forced into early marriage as from age 12 (Ocholi 2002). Ocholi further observed that the regression in basic education is reflected in the fact that the net enrolment rate for girls is very low, with a high drop out rate. Poverty has been known to force most parents to withdraw their children from school. UNICEF (2004) report indicates that some 121 million children are out of school for various reasons and 65 million of them are girls. With the educational rights of 65 million girls unmet, something should be done to ensure that they complete their education. The same report indicates that Nigeria is one of the 25 developing countries of the world with low enrolment rates for girls, gender gap of more than $10 \%$ in primary education and with more than 1 million girls out of school. This is a problem that requires emergency action if the nation is to advance technologically, considering the multiplier and intergenerational benefits derivable in the education of the girl child. It is the aim of this study, therefore, to find out reasons why girls dropout of school in Edo State and, consequently, based on the findings proffer counselling strategies that could be adopted in order to check the incidence of drop out from school among girls in Edo State.

\section{Method of Study}

To guide this investigation, one research question was formulated.

\section{Research Question}

What are the reasons for dropping out of school by girls in Edo State?

The descriptive survey design was adopted for this study. The study sought to determine the reasons for dropping out from school among girls in Edo State. The population of the study comprised all girls who dropped out of school and re-enrolled in schools in Edo State. Four primary schools, four secondary schools and four skill acquisition centres were used for the study. A stratified random sampling procedure was adopted in selecting the secondary schools, on the basis of their status i.e. all girls' schools and all co-educational schools. For the primary schools, the upper primary classes were used for the study while for the skill acquisition centres, two government skill acquisition centres, one non-

governmental skill centre and one private skill centre were used for the study. The research instrument used was a checklist on reasons for dropping out of school. 


\section{Results}

Data were analyzed using percentages.

Analysis of the responses of the subjects on reasons for dropping out of school

Table 1: Reasons for Dropout of School by Girls

\begin{tabular}{|l|c|}
\hline \multicolumn{1}{|c|}{ Responses } & $\%$ \\
\hline Poverty & $53 \%$ \\
\hline Poor academic performance & $16 \%$ \\
\hline Bullying by the opposite sex & $10 \%$ \\
\hline Unfriendly school environment & $09 \%$ \\
\hline Distance of school from home & $05 \%$ \\
\hline Pregnancy/early marriage & $04 \%$ \\
\hline Ill health & $01 \%$ \\
\hline Inadequate teaching & $01 \%$ \\
\hline Death of parents & $01 \%$ \\
\hline & $100.00 \%$ \\
\hline
\end{tabular}

\section{Reasons for Dropout of School by Girls}

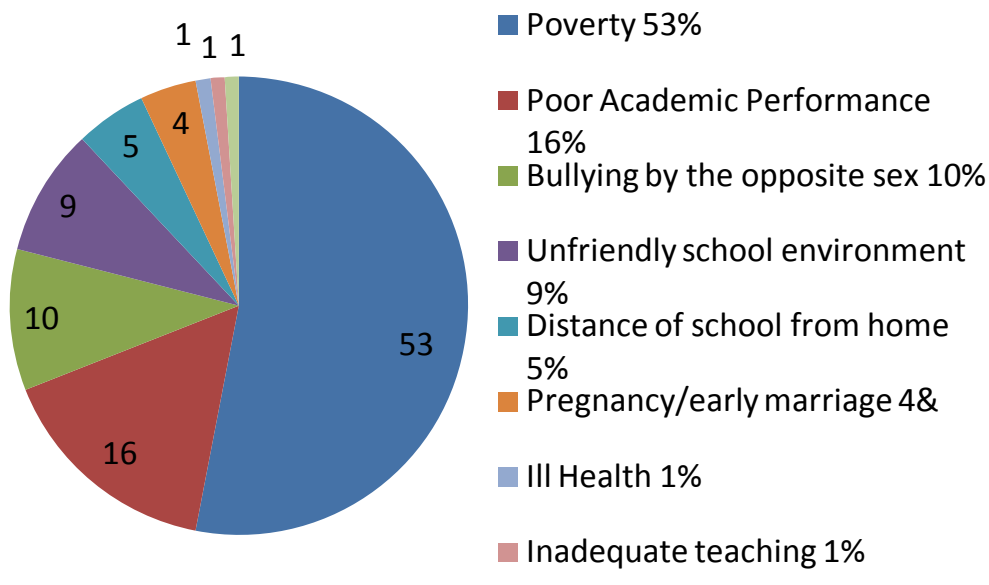

Figure 1: Pie Chart showing the responses of the subjects on reasons for dropout of school among girls in Edo State

Table 1 and the pie chart reveal that poverty ranked highest with $53 \%$ of the respondents indicating that poverty was responsible for their dropping out of school, followed by poor academic performance with 
$16 \% ; 10 \%$ indicated that bullying by the opposite sex was responsible for their dropping out of school, $9 \%$ indicated unfriendly school environment, $5 \%$ indicated distance of school from home, $4 \%$ indicated pregnancy/early marriage, while ill health, inadequate teachers and death of parents had 1\% each.

\section{Discussion of Results}

Data analysis showed that poverty ranked highest (53\%) amongst the reasons for dropout of school among girls. The reason could be as a result of unemployment, lack of sufficient education, retrenchment of workers, poor remuneration. Stringent measures or policies attached to obtaining loans in the banks for the purpose of starting a small-scale-business may be a contributory factor to the high level of poverty in the society. This finding is in agreement with that of UNICEF (2004), which states that some 65 million girls are out of school for various reasons including poverty. The analysis also showed that poor academic performance ranked second $(10 \%)$ in accounting for dropout of school among girls. This could be as a result of inadequate learning facilities, genetic make up of the individual and lack of motivation. Ogletree (1992) found that the main reason for first year students dropping out of school centred on dissatisfaction and frustration with academic programme. This finding is also supported by that of Sigworth (1995) who opined that one predictive factor that accounts for high incidence of dropout was failure in examinations. Bullying by the opposite sex was third in ranking (9\%). This finding is in line with that of Azikiwe (2000), who found that bullying and sexual harassment of adolescent girls by males are some factors responsible for dropout of school by girls. Unfriendly school environment and distance of school from home both ranked fourth and fifth. This could be as a result of biased curriculum, teachers' unfriendly relationship to the girls; some parents may withdraw their girls from school for these reasons. Rosenzwig (1998) reported that children's perception of school affects academic performance.

Pregnancy and early marriage was sixth in ranking (1\%). This may be as a result of culture, peer influence, lack of sex education, and poverty. This finding is in line with the findings of Mohammed (2000) who opined that a girl may be withdrawn from school if a good marriage prospect arises. Ill health and death of parents ranked next with $(1 \%)$ respectively; some girls dropout of school as a result of ill health. WHO (2000) observed that a child may leave school as a result of some personal crises like illness, accident or physical disability. Girls also dropout of school as a result of the death of parents; this is more so if such parent is 
the bread winner of the family, his/her demise would signal the end of educational pursuit for the children especially the girl child.

\section{Conclusion and Recommendations}

This study investigated reasons for dropout from school amongst girls in Edo State. The conclusion drawn from the study is that poverty and poor academic performance greatly account for reasons for dropout from school amongst girls in Edo State. In other words the economic level or status of the family greatly affects the continued stay of the girl child in school.

It is recommended, therefore, that school authorities should provide conducive atmosphere for learning, in which the adolescent girls can easily adapt to and complete their education. Curriculum planners should be counselled on the need to be gender friendly in planning school curriculum. Counsellors should also enlighten parents and the general public through jingles in television and radio on the multiplier benefits derivable from educating the girl child.

\section{Implication for Counselling}

Counsellors should identify indigent students, who are likely to dropout of school as a result of poverty, and help negotiate some form of scholarship or financial assistance for them. Adolescent girls who are not doing well academically should be identified by the counsellors and remedial classes should be organized for them.

The male students and teachers in schools should be counselled on the need to relate more positively to the girls. All forms of sexual harassment and bullying should be discouraged. There is need for personal social counselling either in group or individual basis where all concerned are counselled.

\section{References}

Alika, H.I. \& Egbochuku, E.O. (2009). Vocational Interest, Counselling, Socio-economic Status and Age as Correlates of Re-entry of Girls into School in Edo State. Edo Journal of Counselling, Vol. 2 (1), 9-16.

Azikiwe, U. (2000). Education for special target group. Women Education in the $21^{\text {st }}$ Century Africa and its Implication for $21^{\text {st }}$ Century. Journal of Education for National Development and International Cooperation. 4(1), 57-76.

Egbochuku, E.O. (2002). Counsellors as Facilitators for the Successful Implementation of the Universal Basic Education Scheme in Nigeria, in 
J.A. Aghenta and D. Awanbor (eds.). The Nigerian Academy of Education, Proceedings of the $15^{\text {th }}$ Annual Congress of the Nigerian Academy of Education. Ambik Press Limited, Benin City. 359-370.

Mohammed, S.I. (2000). Female and girl child education in Nigeria. Proceedings of the Educational Mini Summit, held on 29th November 2000 at Abuja, Nigeria.

Ocholi, E.F. (2002). The girl child is vulnerable in access to quality education. Counselling intervention for gender equality. A paper presented at the $26^{\text {th }}$ annual conference of the counselling association of Nigeria, Benin City.

Ogletree, E.J. (1992). Analysis of the non-retention of Chicago Urban University First-year Student. A Research Report Published by Chicago Urban University. Illinois.

Osakwe, G., Osagie, J., Madunagu, B.I. \& Usman, H. (1995). Research Findings into Reproductive rights of Women in Nigeria. International Rights Action Group.

Rosenzwig, M.R. (1998). Evaluating the effects optimally distributed public programmes. America Economic Review, 76 (4), 461-482.

Sigworth, D. (1995). "A study on student withdrawal". A Research Report Published by School Craft College. Livinia, Michigan.

UNICEF, (2003). Girls education progress analysis and achievement in 2002. Medium - Term Strategic Plan 2002 - 2005. UNICEF, New York. 6, 11-15.

UNICEF, (2004). The state of the world's children. Girls Education and Development, 4, 34-35.

World Health Organization (2000). World Health Report, Geneva WHO. 